\title{
Participatory Assessment of Promising Rice Lines in Senegal
}

\author{
T. Guèye ${ }^{1}$, S. Gaye ${ }^{2}$
}

\author{
${ }^{1}$ University of Thies, Superior National School of Agriculture (ENSA), BP A296, Thies, Senegal \\ ${ }^{2}$ Africa Rice Center (AfricaRice), Station Ndiaye, Ndiaye, Saint-Louis, Senegal
}

\begin{abstract}
The objective of this study is to improve dissemination of improved varieties in Senegal. The involvement of small farmers from the beginning of development of a new variety of processes and taking account of their selection criteria, have contributed greatly to the success of participatory research method. It can promote greater ownership of technological innovation by targeted stakeholders and facilitates its widespread dissemination. A total of 44 promising lines and 2 controls were tested under irrigated conditions in two locations in the Senegal River Valley at Ndiaye and Fanaye, during the rainy season. Around 68 small farmers leaders from 26 villages participated in this study. Farmers were particularly interested to factors of production, and to a lesser extent, to constraints of the environment. Of the 44 lines tested, eight 8 were selected by small farmers, including 5 intraspecific hybrids and 3 interspecific hybrids. The best grain yields obtained on the two sites combined are around 6 t.ha $^{-1}$. The sociological study highlighted the typology of farms with a variety of ethnic groups. Most farmers are of advanced age, between 40 and 60 years. The distribution of the harvested products varies according to the location with a strong option for the marketing of products harvested at Ndiaye, where only $1 / 3$ of the harvest is consumed, the vast majority of production is intended for Sale. At Fanaye by against, commercial dynamics is less pronounced with a distribution into two equitable shares of production, one of which is intended for selfconsumption and the other for sale.
\end{abstract}

Keywords: Rice, Participatory Research, Small farmers, Performances, Sociology.

\section{Introduction}

Participatory Research has become a fast and effective method of diagnosis and sustainable dissemination of technological innovations (Groote et al, 2013; Akpo, 2012). The involvement of farmers in the development of a new technology process and the consideration of their selection criteria, have contributed to the success of this method (Raman et al, 2011; Trouche, 2001 ; Thapa et al., 2009) and used to refine the varietal development strategies to increase the chances of adoption and dissemination of varieties (Groote et al., 2013). The advantages of the method in terms of rapid adoption and at less cost of new varieties, were quickly understood and widespread in Asian countries like India or Nepal (Joshi et al 1997. Witcombe et al. , 2001). In the West African region, characterized by high rice imports with a $60 \%$ self-sufficiency (Mendez and Bauer, 2011), the low dissemination of new varieties at the producers, usually made up of small farmers practicing family farming is one of major constraints to sustainable production improvement. The lack of a structured partnership involving small farmers from the start of the process of introduction or development of improved varieties is a bottleneck, which does not promote a good dissemination and appropriation of new improved varieties in farmers' fields, despite strong demand from farmers in efficient varieties. In northern Senegal, on all the area planted in the valleys of the Senegal River in irrigated rice conditions, only a few certified varieties are being cultivated, including three old varieties like sahels (Sahel 108, Sahel 201 and Sahel 202 ), which have however been introduced and approved for over 20 years. Thus, expanding the genetic diversity of irrigated rice through the dissemination of promising lines with good yield potential (Traore et al., 2010), through an interspecific crossing process, and participatory research trial, will make available to producers in the region, new varieties, productive, and more adapted to local constraints. Interspecific lines, or NERICA, developed with good yield potential, are a source of sustainable improvement in yields both in irrigated conditions but especially in upland and lowland where yields are two to three times lower. Good ownership by the producers of new varieties, which must meet consumer demands

This article is published under the terms of the Creative Commons Attribution License 4.0

Author(s) retain the copyright of this article. Publication rights with Alkhaer Publications.

Published at: http://www.ijsciences.com/pub/issue/2016-06/

DOI: $10.18483 /$ ijSci.1076; Online ISSN: 2305-3925; Print ISSN: 2410-4477 
for quality, is a prerequisite for successful dissemination of new technological innovations.

This evaluation aims to promote the integration of real needs of small farmers in the process of development and diffusion of promising new varieties and lines, through a participatory research approach.

\section{Material and method}

The plant material is composed of 44 rice lines, including 15 interspecific lines and 29 intraspecific lines. Two varieties widely grown in the Senegal River valley, such as Sahel 108 and Sahel 202, short and medium cycle varieties respectively, were used as controls in this study. That makes a total of 46 varieties and lines. The seeds were first sown in the nursery. After three weeks, the seedlings were transplanted in an experimental device consists of a single block without repeating. Each line is transplanted into a plot of $6 \mathrm{~m}^{2}$ with $20 \times 20 \mathrm{~cm}$ spacing between poquets and between lines. Fertilization with urea and Diammonium Phosphate (DAP) with the formula 120-60-60 (N, P2O5, K2O) was used. Phosphorus and potassium were used as basic fertilizer at planting and nitrogen as urea, is used as fertilizer in cover in three (3) applications: Early tillering ( $40 \%$ of dose), panicle initiation $(40 \%$ of dose) and Montaison of the panicle in the stem (20\% of the dose). The small farmers, who are mostly leaders in their respective villages, were invited to the experimental center, to make the choice according to their criteria, among the 46 varieties and lines, which are tested. The selection of lines has focused on different characters that interest producers in a new variety. This evaluation was conducted during two visits organized at specific physiological stages during the cycle of the plant, including a visit to the stage flowering and another at Maturity. Each small farmer selected 5 lines by completing an evaluation form designed for this purpose and explaining the characters that motivated its choice. Socio economic data to describe producers were also compiled in survey forms. Meanwhile farmers tours, agronomic traits related to the cycle, yield, grain type, height, panicle shape, and yield components were also measured in the field using standard method.

\section{Results}

Criteria that guided the choice of small farmers:

The different criteria that guided the choice of small farmers across all cumulative sites at different phenological stages are summarized in Table 1 . According to the preferences indicated by farmers and hierarchical way, characters related to grain yield, the panicle exertion, tillering, grain shape, plant height, cycle, and the type of plant, were most scored and represent $97.39 \%$ of the choice of producers. The characters related to adaptation to the constraints of the environment such as salinity, weeds, cold, get a cumulative score, which is around $2.61 \%$. The most popular character from small farmers, according to their affinities, can be divided into two groups, which emphasizes performance indicators for the yield and quality of the grain, on the one hand, and on the other hand, performance indicators related to adaptation to the context of the environment of the experiment (Figure 1).

\section{The varieties selected by farmers}

The eight (8) best lines chosen by small farmers on both sites during the two stages of the trial were ranked in Table 2 . The mean frequency choices vary between $0.13 \%$ and $7.94 \%$.

\section{Agronomic data}

Grain yields on all sites are summarized in Table 3. The average yields of lines tested varies from 3.25 t.ha-1 to 6.66 t.ha-1. In this group, there are lines already identified by the farmers on their own terms. This is lines WAS197-B-6-3-11, and WAS 191-7WAB-1-WAS-1, which are the second and 6th place respectively, compared to the performance.

\section{Socio-demographic characteristics of producers}

The distribution of producers based on ethnicity, on both sites is illustrated in Table 4 .

The distribution of farmers by age, across the two sites is summarized in Table 5.

\section{Distribution of the mean surface cultivated by type of small farmer}

There are three different types of farms, depending on the size of the farm and the resources available. Can be distinguished (1) the large irrigated areas (GPI), (2) intermediate Irrigated Perimeters (PI), and (3) irrigated village perimeters (PIV). The PI and PIV occupy a small area compared to the GPI. Rice percentage for the sale and consumption, both sites is shown in Table 6.

\section{The rice varieties:}

As part of our survey, most farmers recognize that he never tested new varieties or lines as a partner and actor in a participatory and inclusive process. They just limited to use released varieties proposed by research, as downstream actor in the value chain. This is varieties Sahel 108, Sahel 201, Sahel 202 and IR 1529, and former introductions. They appreciated the participatory approach, which they consider an innovation that can enable them to participate from the beginning to the end of the selection process of new varieties and make proposals on improving agronomic characters.

\section{The constraints related to production:}

Discussions with farmers revealed a number of constraints, which impede the development of rice 
and are related to:

- The availability and accessibility of certified seed;

- Access to credit;

- The availability of farm machinery for crop intensification;

- The biotic stress (damage by birds, weeds) and abiotic (salinity, iron toxicity);

- Quality of local rice compared to imported rice.

\section{Discussions}

\section{Criteria chosen by the small farmers}

Analysis of the criteria for selection of farmers, illustrated in Table 1 and Figure 1 shows that farmers are primarily interested in traits related to agronomic performance and quality such as yield, plant type, grain shape and cycle, with higher cumulative scores $96 \%$. Irrigated rice farming is intensive agriculture. The increase in productivity at farm levels for grain quality is a prerequisite for improving the quality of milled grains and competitiveness compared to imported rice, which is based on a particularly good control technologies production and processing (Gahiro, 2011). The characters associated with resistance or adaptation to environmental stresses, with a cumulative score low of $2.37 \%$, is the weak point in the selection criteria of the small farmers, who do not give all due attention to environmental factors which impact negatively on the agronomic performance of varieties. In a context of climate change, whose effects on water availability and agricultural performance are real (Ye and al. 2015), better awareness of farmers on the impact of biotic and abiotic stress on crops, through targeted training, will contribute to a better account by the farmers of the environmental dimension and its potential effects on crop performance.

\section{Favorite varieties of small farmers}

Among the eight (8) best choice of small farmers, which are shown in Table 2, there was seven (7) intra-specific lines, and two (2) interspecific lines (WAS191-7-WAB-1-WAS-1, and WAS127-12-1-2$3)$. This shows that the farmers of the two sites (Ndiaye and Fanaye) are interested in these two types of lines especially intra-specific lines, including those from the series of WAS173, who presented the best average grain yields. The duration sowing maturity seems to be variously appreciated by sites. The farmers of the site Ndiaye, have far more privileged earliness while those of Fanaye area, chose the varieties with average cycle or a long cycle. Discussions with farmers highlighted a preference for early cycles in the delta (Ndiaye) unlike the peasants of the Middle Valley (Fanaye), which seem to opt for medium or long cycles. The Delta area is characterized by salinity of soil and seasonal temperature drops. Early varieties allow them to harvest before the November drops in temperature that reduce overwintering crop yields for longer cycles, and also to practice double cropping rice / rice. Precocity is also an advantage during the semi belated, hence their preference for short cycle varieties. At Fanaye farmers prefer rather varieties with a medium or long cycle, which they consider more profitable because of better grain filling unlike the short-season varieties, which are characterized in this site by poor filling seeds.

\section{Agronomical measures}

The analysis of Table 3 shows the cumulative average yields on the two sites, which vary between 6.66 and $3.25{\mathrm{t} . h a^{-1}}^{-}$The best yields were obtained by the intra-specific lines WAS 33-BB-15-1-4-5 (6.66 t $\left.\mathrm{ha}^{-1}\right)$, and WAS 197-B-6-3-11 (6.57 t.ha-1) and interspecific WAS 122-7-1-1-2 (6.51 t.ha-1). Only seven (7) first varieties outperform the best control represented by the Sahel 108 (6.25 t.ha-1). The most productive lines in terms of grain yield, which listed the small farmers, with good agronomic performance as declined on Table 3, are formed by the lines WAS 197-B-6-3-11 (6.57 t.ha $\left.{ }^{-1}\right)$, WAS 191-7-WAB-1WAS-1 (6.27 t.ha $\left.{ }^{-1}\right)$ and WAS 127-12-1-2-3 (5.37 tha $\left.^{-1}\right)$. These lines follow the same hierarchy as well as the choice farmers that a result of measures of agronomic data. This suggests that the choice farmers incorporates many of the factors that contribute to getting a good yield, but not all. It is therefore necessary to bring together the conditions of better choice, to establish a multidisciplinary partnership actively integrating farmers, who have to work in close collaboration with researchers. Analysis of the favorite characters from the farmers in a new variety gives an idea about the architecture of the ideal variety for which the small farmers of cultivating rice under irrigated conditions would need. It must have (i) a good grain yield through a tassel drooping with the weight of grains and well supplied with grains, (ii) a good excertion of the panicle, which allows the spikelets bearing the seeds to be well erected and foster a good fertilization of flowers, (iii) a good tillering, which promotes better performance and contributes to a good adaptation to weeds, (iv) long and slender grains that are specific indicators of quality for consumers in the regions (v) a type of plant with a semi dwarf size $(80-110 \mathrm{~cm})$, highly efficient under irrigated condition and finally (vi) a medium or long-cycle (in rainy season) or a short cycle in hot dry season, to promote the double cropping rice / rice. A schematic illustration of the morpho-type variety desired by farmers in irrigated conduction in the Senegal River valley, is declined below (Figure 1):

The first 8 lines selected in Table 2, particularly the WAS 197-B-6-3-11 and WAS 191-7-WAB-1-WAS1 , which showed good agronomic performance, seem more or less meet with these 


\section{socio-economic analysis}

The socio-demographic survey of our sample of small farmers at Ndiaye and Fanaye shows the cultural interaction between the different ethnic groups composed of Wolof, Fulani, Jola, Serere, Bambara and Moors (Table 4). Meeting place and miscegenation, the river Senegal sees developing around the valley of different ethnicities whose agriculture is their main activities.characteristics. The analysis of our sample showed a greater percentage of Wolof (60\%) and Fulani (24\%) at Ndiaye, while at Fanaye the Fulani (74.35\%), Wolof (12.82\%) and Moors (10.25\%) are the most represented. Compared to the age (Table 5), farmers are divided into three classes with a first group aged between 20 and 40 years (class 1), another whose age is between 41 and 60 years (class 2) and a third group whose age is greater than 60 . So at Ndiaye, the majority of farmers $(80 \%)$ are Mature Adult (40-60 years), and generally have Irrigated Perimeter Villager (PIV), they operate only in part for lack of financial resources. Young people are poorly represented on the two study sites, but with a better representation at Fanaye $(38.46 \%)$ than Ndiaye (12\%) (Table 5). The use of harvested produce is varied by site (Table 6). At Ndiaye, $70 \%$ of the crop is being sold while in Fanaye is half of the crop is being sold, the other half being intended for consumption. The moderate selling rice at Fanaye, is explained by the diversification of income of these populations mainly Fulani, who are also livestock farmers and can diversify their income by operating their livestock.

\section{Conclusion}

Small farmers in the Senegal River Valley have particularly favored in their choices, economic performance indicators such as yield, grain quality, cycle and to a lesser extent adaptation to environmental constraints. The priority given to production factors may be due to the intensive nature of irrigated rice in the valley with a structured partnership between producers and funding institutions. However, the environmental adaptation of indicators should be better taken into account because they contribute to performance improvement. Better awareness of farmers through capacity enhancements on biotic and abiotic stresses, and more generally on the effects of climate change on the environment, will help to achieve this objective. The socio-economic survey provided insight into the typology of farms but also to have a greater legibility of the pyramid of the sample analyzed ages of farmers and constraints they face. Among these constraints, the availability and accessibility of certified seeds occupy a good place. Participatory research is a method well appreciated by producers. It is a fruitful partnership between researchers and producers, which should be extended to all actors of the value chain in order to take into account all the concerns of the various stakeholders to translate research topic. This will allow to significantly increase the chances of adoption and sustainable dissemination of new varieties from this process.

\section{References}

1) Akpo E., Vissoh P.V., Tossoua R.C., Cranec T., Kossou D.K., Richards P., Stomph T.J., and Struik P.C. (2012). A participatory diagnostic study of the oil palm (Elaeis guineensis) seed system in Benin. NJAS - Wageningen Journal of Life Sciences 60- 63 (2012) 15- 27.

2) Joshi K. D. Subedi M., Rana R. B,. Kadayat K. B, and Sthapit B. R. (1997). Enhancing on-farm varietal diversity through participatory varietal selection: A case study for chaite rice in Nepal. Experimental Agriculture (Exp. Agric.) ISSN 0014-4797 CODEN EXAGAL. In: Experimental agriculture (1997), vol. 33, pp. 335-344.

3) sociales 2006/4 (no 164), p. 23-50.

4) Mendez P. V. et Bauer J. M. (2011). Qui approvisionnera l'Afrique de l'ouest en riz importé. In : Grain de sel nº 54-56, pp. 35-35, 2011

5) Gahiro L. (2011). Compétitivité des filières rizicoles burundaises : le riz de l'Imbo et le riz des marais. (Thèse de doctorat en Français). Belgique, Université de Liège Gembloux Agro-Bio Tech. 187 p., 37.

6) Groote D.H., Dema G., Sonda G.B.and Gitong Z.M. (2013). Maize for food and feed in East Africa-The farmers' perspective. Field Crops Research 153 (2013) 22-36

7) Raman A., Ladha J.K., Kumar V., Sharma S., and Piepho H.P. (2011). Stability analysis of farmer participatory trials for conservation agriculture using mixed models. Field Crops Research 121 (2011) 450-459

8) Thapa D.B., Sharma R.C., Mudwari A., Ortiz-Ferrara G., Sharma S. Basnet R.K.,

9) Witcombe J.R., Virk D.S, and Joshi K.D. (2009).Identifying superior wheat cultivars in participatory research on resource poor farms. Field Crops Research 112 (2009) 124-130

10) Traoré K, Bado BV, Gueye T, and Gaye S (2010). Grain yield performance of interspecific irrigated rice genotypes in the Senegal river valley, as affected by cropping season. West African Journal of Applied Ecology, vol 17, 2010

11) Trouche G. (2001). L'amélioration variétale participative au CIRAD : historique et justification pour la création d'un groupe de réflexion sur ce thème. In: Sélection participative: Impliquer les utilisateurs dans l'Amélioration des plantes. Sélection participative, Montpellier, 5-6 Septembre 2001, pp. 18-23.

12) Witcombe J. R., Joshi, K. D., Rana R. B. and Virk D. S. (2001). Increasing genetic diversity by participatory variatal selection in high potential production systems in Nepal and India. Euphytica (Euphytica). In: Breeding for low-input conditions and consequences for participatory plant breeding 2001, vol. 122, n³ (25 ref.), pp. 575-588. Ed. Springer.

13) Ye K., Yang X., Dai S., Chen G., Li Y., and Zhang C. (2015). Effects of climate change on suitable rice cropping areas, cropping systems and crop water requirements in southern China. Agricultural Water Management 159 (2015) 35-44. 


\section{Figures}

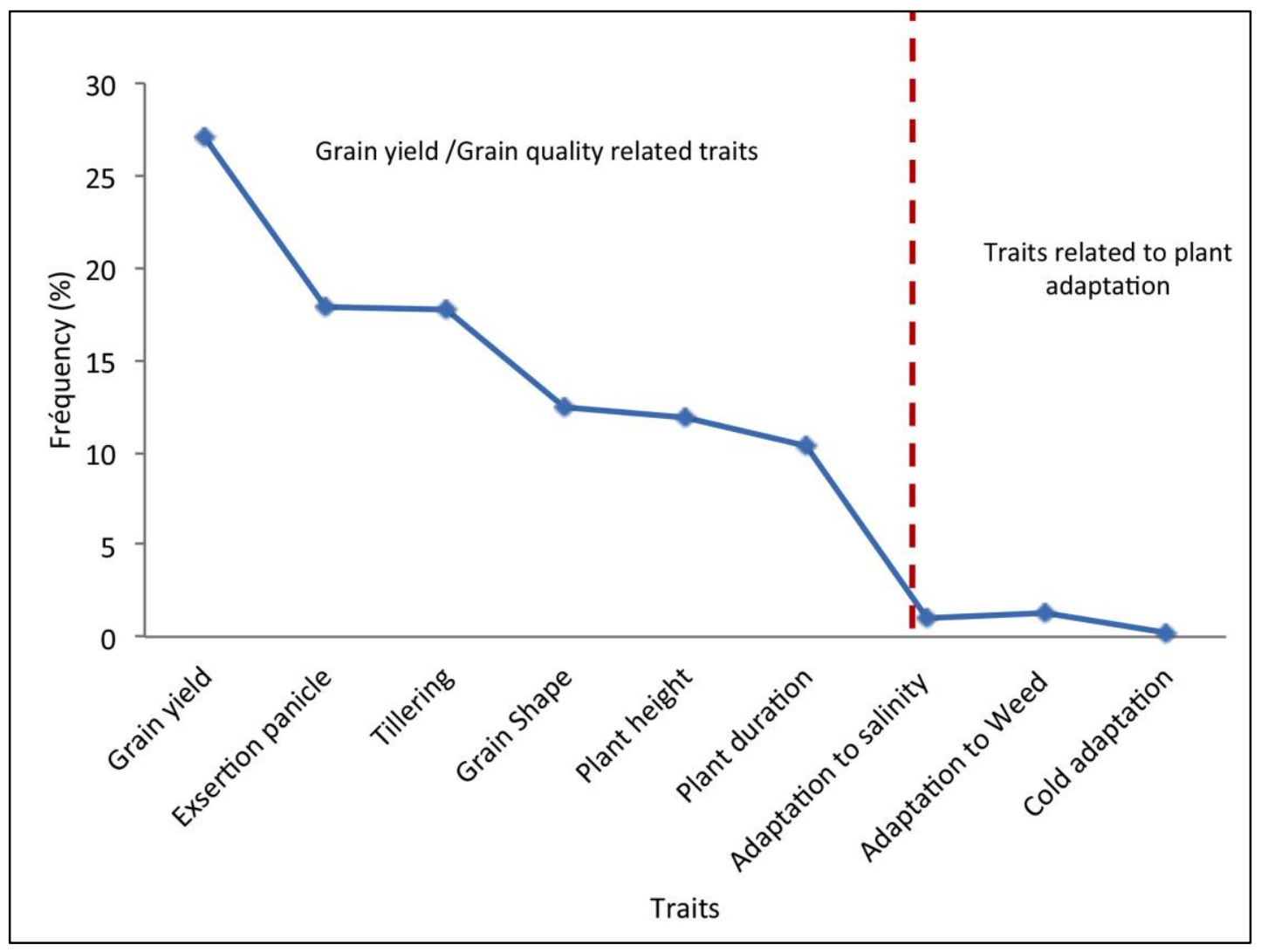

Figure 1 : Indicators targeted agricultural performance by small farmers

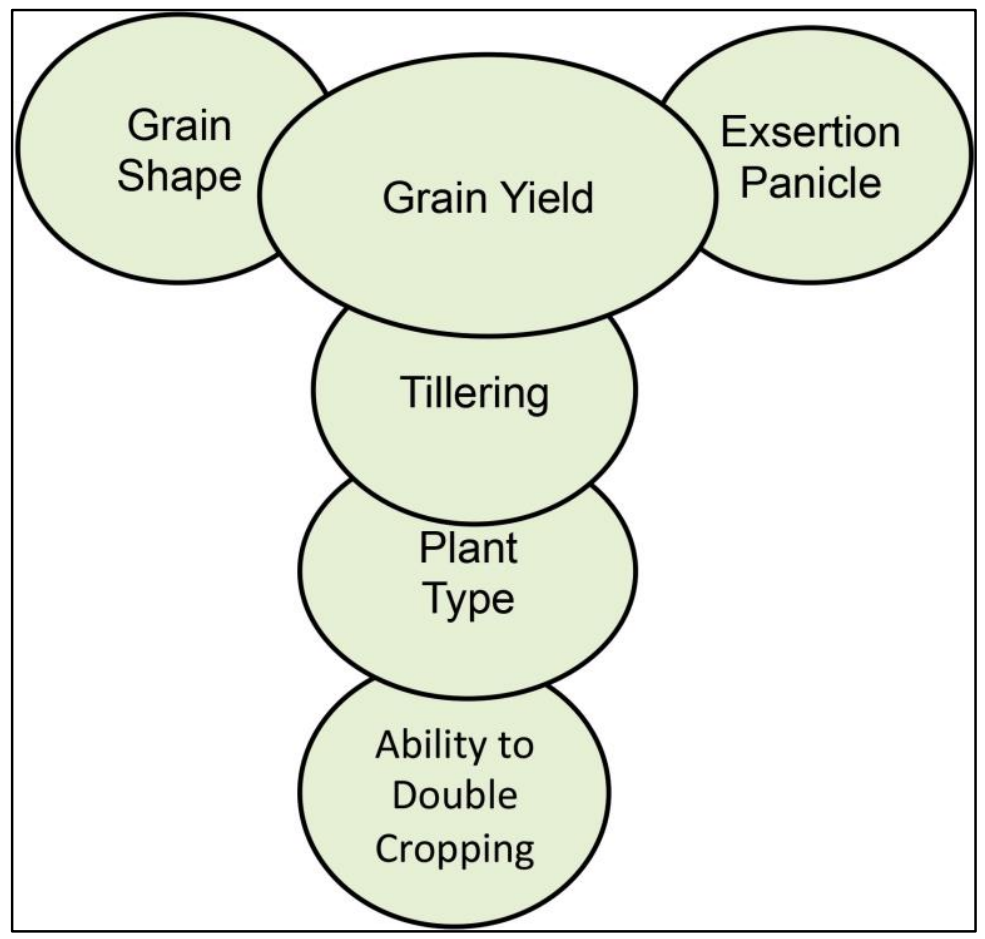

Figure 2 : Morphotype varieties desired by the small farmers of the area Tableaux 
Table 1 : Main characters chosen by small farmers on the tested lines

\begin{tabular}{|c|c|c|c|c|}
\hline & $\begin{array}{l}\text { Sowing-Flowering } \\
\text { Duration* }\end{array}$ & Ecart type & $\begin{array}{l}\text { Sowing-Maturity } \\
\text { Duration* }\end{array}$ & Ecart type \\
\hline Variables & \multicolumn{3}{|l|}{ Frequency $(\%)$} & \\
\hline Grains Yield (en t.ha ${ }^{-1}$ ) & 25,24 & 1,43 & 28,93 & 4,095 \\
\hline Exsertion panicle & 17,30 & 1,745 & 18,32 & 4,56 \\
\hline Tillering & 17,70 & 2,14 & 17,80 & 1,465 \\
\hline Grain shape (en cm) & 11,90 & 4,765 & 12,89 & 1,785 \\
\hline Plant hight (en $\mathrm{cm}$ ) & 13,01 & 0,32 & 10,86 & 1,065 \\
\hline Plant duration (days) & 11,19 & 2,30 & 9,61 & 4,115 \\
\hline Adaptation to salinity & 1,66 & 1,665 & 0,46 & 0,46 \\
\hline Adaptation to weeds & 1,98 & 1,985 & 0,655 & 0,65 \\
\hline $\begin{array}{lll}\text { Aptation } & \text { to } & \text { low } \\
\text { temperature } & & \\
\end{array}$ & 0 & 0 & 0,46 & 0,46 \\
\hline
\end{tabular}

${ }^{*}$ Average

Table 2 : Average frequencies of lines selected by small farmers on all location

\begin{tabular}{|l|l|l|l|l|l|}
\hline & $\begin{array}{l}\text { Sowing-Flowering } \\
\text { Duration* }(\%)\end{array}$ & $\begin{array}{l}\text { Ecart } \\
\text { type }\end{array}$ & $\begin{array}{l}\text { Sowing-Maturity } \\
\text { Duration* (\%) }\end{array}$ & Ecart type \\
\hline 1 & & & & \\
\hline 2 & Wines & 9,19 & 0,80 & 6,69 & 2,07 \\
\hline 3 & WAS 197-B-6-3-11 & 9,33 & 2,88 & 5,53 & 1,68 \\
\hline 4 & WAS 173-B-B-6-4 & 4,95 & 1,72 & 6,68 & 1,01 \\
\hline 5 & WAS 173-B-B-10-6-5 & 4,19 & 4,19 & 7,20 & 1,05 \\
\hline 6 & WAS 173-B-B-5-3 & 5,00 & 5,00 & 5,26 & 3,20 \\
\hline 7 & WAS 191-7-WAB-1-WAS-1 & 6,56 & 0,11 & 3,22 & 2,45 \\
\hline 8 & WAS 127-12-1-2-3 & 3,66 & 3,01 & 5,64 & 5,12 \\
\hline & Control & & 2,35 & 5,51 & 4,48 \\
\hline & Sahel 202 & 5,73 & & & 0,40 \\
\hline & Sahel 108 & 0 & 3,15 & 5,78 & 0,26 \\
\hline
\end{tabular}


Table 3 : average agronomic performance measured lines on all location

\begin{tabular}{|c|c|c|}
\hline Rang & Lines & $\begin{array}{l}\text { Average grain yield } \pm \\
\text { Ecart type }\left(\text { t.ha }^{-1}\right)\end{array}$ \\
\hline 1 & WAS 33-B-B-15-1-4-5 & $6,66 \pm 0,42$ \\
\hline 2 & WAS 197-B-6-3-11 & $6,57 \pm 0,03$ \\
\hline 3 & WAS 122-7-1-1-2 & $6,51 \pm 0,96$ \\
\hline 4 & WAS 207-B-B-3-3-2 & $6,36 \pm 0,27$ \\
\hline 5 & WAS 122-IDSA-14-WAS-B-FKR-1 & $6,33 \pm 1,20$ \\
\hline 6 & WAS 191-7-WAB-1-WAS-1 & $6,27 \pm 0,71$ \\
\hline 7 & WAS 127-12-1-6-3-1 & $6,26 \pm 0,37$ \\
\hline 8 & WAS 191-7-WAB-1-WAS-2 & $6,24 \pm 0,40$ \\
\hline 9 & WAS 191-7-WAB-1-WAS-3 & $6,22 \pm 0,40$ \\
\hline 10 & WAS 187-7-WASB-1-WAS-1 & $6,11 \pm 1,01$ \\
\hline 11 & WAS 207-B-B-3-3-2-1 & $6,10 \pm 0,04$ \\
\hline 12 & WAS 191-15-FKR-1 & $5,93 \pm 0,38$ \\
\hline 13 & WAS 30-11--4-6-2-2-1 & $5,90 \pm 1,18$ \\
\hline 14 & WAS 191-1-7-FKR-1 & $5,80 \pm 0,08$ \\
\hline 15 & WAS 62-B-B-17-1-1-3 & $5,79 \pm 0,17$ \\
\hline 16 & WAS 21-B-B-20-4-3-3 & $5,78 \pm 0,33$ \\
\hline 17 & WAS 62-B-B-17-1-1-1 & $5,72 \pm 0,55$ \\
\hline 18 & WAS 202-B-B-1-1-2 & $5,65 \pm 1,42$ \\
\hline 19 & WAS 186-B-6-B-1 & $5,62 \pm 0,45$ \\
\hline 20 & WAS 191-1-7-FKR-1 & $5,48 \pm 0,02$ \\
\hline 21 & WAS 127-12-1-2-3 & $5,37 \pm 0,38$ \\
\hline 22 & WAS 161-B-9-2 & $5,36 \pm 0,31$ \\
\hline 23 & WAS 203-B-B-1 & $5,32 \pm 1,84$ \\
\hline 24 & WAS 173-B-B-5-3 & $5,28 \pm 0,22$ \\
\hline 25 & WAS 55-B-B-2-1-2-5 & $5,26 \pm 0,16$ \\
\hline 26 & WAS 122-IDSA-10-WAS-1-1-FKR-1 & $4,95 \pm 1,8$ \\
\hline 27 & WAS 202-B-B-1-1-3 & $4,92 \pm 0,51$ \\
\hline 28 & WAS 62-B-B-14-1 & $4,91 \pm 0,09$ \\
\hline 29 & WAS $122-7-2$ & $4,77 \pm 0,76$ \\
\hline 30 & WAS 63-22-5-9-10-1 & $4,77 \pm 0,63$ \\
\hline 31 & WAS 207-B-B-3-1-1 & $4,67 \pm 0,34$ \\
\hline 32 & WAS 169-B-B-4-2-9 & $4,66 \pm 1,46$ \\
\hline 33 & WAS 173-B-B-5-3B & $4,41 \pm 1,35$ \\
\hline 34 & WAS 173-B-B-10-6-5 & $4,23 \pm 0,21$ \\
\hline 35 & WAS 122-IDSA-10-WAS-10-WAB-2-WAS-1 & $4,13 \pm 3,10$ \\
\hline 36 & WAS 173-B-B-10-6-2 & $4,12 \pm 0,53$ \\
\hline 37 & WAS 207-B-B-3-3-2-2 & $4,09 \pm 1,38$ \\
\hline 38 & WAS 173-B-B-9-5 & $4,08 \pm 0,55$ \\
\hline 39 & WAS 173-B-B-2-1-5 & $4,01 \pm 1,23$ \\
\hline 40 & WAS 173-B-B-4-2 & $3,96 \pm 1,35$ \\
\hline 41 & WAS 173- B-B-10-6-2A & $3,76 \pm 1,35$ \\
\hline 42 & WAS 173-B-B-6-4 & $3,58 \pm 0,01$ \\
\hline 43 & WAS 173-B-B-6-2-2 & $3,5 \pm 0,78$ \\
\hline \multirow[t]{4}{*}{44} & WAS 197-B-4-1-5 & $3,25 \pm 1,85$ \\
\hline & Control: & \\
\hline & Sahel 108 & $6,25 \pm 1,01$ \\
\hline & Sahel 202 & $4,99 \pm 0,12$ \\
\hline
\end{tabular}


Table 4 : Distribution of farmers by ethnic group on different sites

\begin{tabular}{|l|l|l|l|l|}
\hline & Ndiaye & \multicolumn{3}{l|}{ Fanaye } \\
\hline Ethnic groups & Effectifs & $\%$ & Effectifs & $\%$ \\
\hline Wolof & 15 & 60 & 5 & 12,82 \\
\hline Peulhs & 6 & 24 & 29 & 74,35 \\
\hline Diolas & 1 & 4 & - & - \\
\hline Serers & 1 & 4 & 1 & 2,56 \\
\hline Bambaras & 1 & 4 & - & \\
\hline Maures & 1 & 4 & 4 & 10,25 \\
\hline Total : & 25 & 100 & 39 & 100 \\
\hline
\end{tabular}

Table5 : Distribution of farmers by age at Ndiaye and Fanaye

\begin{tabular}{|l|l|l|l|l|}
\hline & Ndiaye & Fanaye & \\
\hline Classes d'âges & Effectifs & $\%$ & Effectifs & $\%$ \\
\hline Classe 1 (20-40) & 3 & 12 & 15 & 38,46 \\
\hline Classe 2 $(41-60)$ & 20 & 80 & 24 & 61,54 \\
\hline Classe 3 $>60)$ & 2 & 8 & 0 & 0 \\
\hline Total : & 25 & 100 & 39 & 100 \\
\hline
\end{tabular}

Table 6 : Distribution of products harvested by site

\begin{tabular}{|l|l|l|}
\hline Locations & Sale $(\%)$ & Self Consumption $(\%)$ \\
\hline Ndiaye & 70 & 30 \\
\hline Fanaye & 50 & 50 \\
\hline
\end{tabular}

